https://doi.org/10.19195/2084-2546.29.8

\title{
VIRGINIA BONATTO
}

ORCID: 0000-0001-8412-8025

Universidad Nacional de La Plata

Correo: abonatto@fahce.unlp.edu.ar

\section{El palomo cojo (1991) de Eduardo Mendicutti. Hacia una memoria camp}

\author{
Palabras clave: franquismo - memoria colectiva - novela - Eduardo Men- \\ dicutti - camp.
}

\section{Resumen}

Este trabajo aborda la novela El palomo cojo (1991) de Eduardo Mendicutti como un relato sobre el nacimiento de la conciencia abyecta dentro de los cánones sociales, morales y culturales del franquismo en la España de los años cincuenta. El palomo cojo articula tres géneros narrativos relacionados con el yo: la novela autobiográfica, las memorias y el Bildungsroman, y los acondiciona con elementos descriptivos y argumentales de la tradición gótica. La sensibilidad camp aparece como el espacio semántico e ideológico que nuclea y resignifica estas múltiples inscripciones narrativas.

\section{Introducción}

Publicada en 1991, El palomo cojo marcó el inicio del reconocimiento más extendido de la obra del escritor andaluz Eduardo Mendicutti ${ }^{1}$. Este relato de gran contenido autobiográfico se abre con dos epígrafes, uno de ellos perteneciente al poeta griego Yorgos Seferis, que dice: "Allí donde toques la memoria duele" (Mendicutti, 2001: 9) ${ }^{2}$. La cita y su alusión a lo corporal invitan a pensar la problemática de la memoria entendida, además de como hecho simbólico y cultural, como encarnación. La mención al dolor en la antesala de una novela

${ }^{1}$ El palomo cojo apareció en mayo de 1991, en la colección Andanzas de la Editorial Tusquets, con dos reediciones ese mismo año, una en 1994 y otra más en 1995 . En 1994 y 1995 se publican una cuarta y quinta edición. En 1995 es traducida al francés y en 1998 al portugués. En 1995 Jaime de Armiñán y Luis Méndez realizan la adaptación cinematográfica.

2 En adelante, las referencias bibliográficas correspondientes a las citas de esta novela serán indicadas solo mediante números de páginas, de acuerdo con la edición Mendicutti (2001). 
que se encargará precisamente de la tarea de reconstrucción memorialística de un periodo de la vida individual y de una época (España durante los años cincuenta), articula dos instancias que el relato tensionará una y otra vez: el cuerpo y la historia. En El palomo cojo, la memoria silenciada de un sujeto abyecto se anuda con la memoria colectiva, normativa y cohesiva, pero conformada también por lo que se expulsa y reprime (Assmann, 2008: 47). Y esto sucede al ritmo de un despertar sexual queer que, en el contexto de la representación costumbrista de la alta burguesía andaluza de los años cincuenta, adquiere subversión paródica.

Como relato íntimo y retrospectivo, El palomo cojo articula tres géneros del yo: la novela autobiográfica, las memorias y el Bildungsroman; y los acondiciona con elementos descriptivos y argumentales de la tradición gótica. La sensibilidad camp aparece como el espacio semántico e ideológico que nuclea y resignifica estas múltiples inscripciones narrativas. En este trabajo presentaremos, en primer lugar, algunas claves para leer El palomo cojo como relato queer sobre el nacimiento de la conciencia abyecta en el marco de la novela española contemporánea sobre la Guerra Civil y la posguerra, y, en segundo lugar, desglosaremos algunos aspectos camp de esta novela.

\section{Nacimiento de la conciencia abyecta en el marco de la memoria de época}

Centrada exclusivamente en la infancia, El palomo cojo recoge experiencias autobiográficas que se observan en la edad del protagonista (diez años) y en la ubicación espacial y temporal de la trama: una antigua casona de Sanlúcar de Barrameda (pueblo natal del autor) durante el año 1958. La historia, narrada en dieciocho capítulos agrupados en tres partes ("Junio", "Julio" y "Agosto"), recupera los tres meses del verano de 1958 durante los cuales Felipe Jesús Guillermo Calderón Bonasera Lebert (en adelante, Felipe) convalece de una enfermedad no especificada (posiblemente tuberculosis) en la casa de sus abuelos maternos, andaluces bodegueros y representantes de un sector de la alta burguesía venido a menos durante la posguerra. Durante el lapso de ese verano, Felipe atraviesa la instancia más importante y decisiva de su vida: el despertar del deseo homoerótico, que ocurre a partir de sus experiencias con un grupo de adultos bastante excéntrico compuesto por Mary, una de las criadas de la casa, muchacha de comportamientos libertinos y de lenguaje llamativamente soez (estereotipo costumbrista y andaluz de la mujer resuelta); la tía abuela Victoria, rapsoda autoexiliada que regresa junto a un amante italiano porque está quedándose sin dinero; y el tío Ramón, hermano menor de la madre de Felipe, personaje bisexual y trotamundos, quien aparece inesperadamente en casa perseguido por la policía franquista.

El punto de tensión máxima en el desarrollo de la trama se ubica en la tercera parte (capítulo "Los bichos raros") cuando todos estos personajes se reúnen en secreto y de madrugada en el salón más importante de la casona para oír poemas 
de Federico García Lorca recitados por Victoria. Mientras la rapsoda experimenta uno de sus habituales éxtasis artísticos, Ramón manosea a Mary en el sofá, y el orgasmo de la criada se yuxtapone sarcásticamente con las evocaciones gitanas del poeta granadino: "apretó la boca y puso cara de susto, como si acabase de cometer un sacrilegio con aquel gritito mientras tía Victoria, llena de trance, no encontraba la forma de quitarse de encima la pena de los gitanos" (211). Felipe descubre en Mary una sortija de rubí perteneciente a Victoria y cierra el episodio con sus gritos delatores, movidos en verdad por celos amorosos. El equilibrio se romperá definitivamente (Mary es despedida, Ramón se marcha nuevamente y Victoria se encierra por días enteros en su cuarto), pero Felipe ya ha aprendido algo respecto de su lugar en el mundo que será irreversible, y que a pesar de la inocencia con que lo enuncia debe leerse como una instancia fundamental de aprendizaje: "era mucho mejor, más divertido y más emocionante, estar con los bichos raros. Así que no tenía que darme vergüenza cuando se me ocurría que de mayor iba a ser un bicho raro" (212).

Al grupo de adultos mentores se suma la presencia esquiva y misteriosa de otro tío abuelo del pequeño, Ricardo, cuya única ocupación consiste en criar palomas y deambular por las noches, como si fuera un fantasma. De una forma $\mathrm{u}$ otra, todos los adultos retratados en la novela tienen influencia formativa en Felipe y poseen cualidades que los singularizan de un modo que, si bien se acerca al estereotipo y al grotesco, descubre una realidad que condice con la idea de una (hetero)normalidad imposible característica de toda la obra de Mendicutti. En este sentido, se leen también los aconteceres relacionados con otros personajes secundarios, como la bisabuela Carmen y la criada Caridad, cuyos achaques irreverentes resultan orgánicos en relación con el sistema de la (hetero)normalidad nacional-católica. Por un lado, la respetable anciana, que agoniza en su cuarto, perturba el ambiente de la casona, como en las historias góticas, mediante el relato a gritos de antiguas aventuras amorosas que habría tenido de joven con "una cuadrilla entera de bandoleros" en Sierra Morena (32), y tiembla "no de sofocación" sino "de contento" (155) ante la vista de fotografías de hombres desnudos, que Mary coloca frente a sus ojos. Al poner en escena la sospechosa relación de continuidad entre respetabilidad social y desenfreno sexual, la historia de Carmen Lebert resquebraja la apariencia moral y monolítica de una clase, la burguesía acomodada, y de su vínculo con el sistema político e ideológico del franquismo (Carmen chillaba también cuando Victoria insultaba a Franco). Por otro lado, los ataques de invisibilidad y pérdida de las partes de su cuerpo (135) que sufre Caridad, anciana pobre y sin descendencia, emergen como símbolo de la decadencia familiar y metáfora de lo invisible, es decir, de aquello que nadie nombra porque constituye, como los bandoleros de Carmen, la porción abyecta que a un tiempo nutre y amenaza la coherencia de las identidades normalizadas. Así como Victoria se ve obligada a vender sus joyas, la tía Blanca se muda al Barrio Bajo porque se casa con un constructor de menor estatuto social y el negocio familiar no alcanza para sostener el estilo de vida y las costumbres de antaño, las anomalías de Caridad condicen con ese universo en vías de extinción. 
Como en todas sus referencias a hechos y discursos de adultos, el narrador, en su calidad de memorialista y testigo de sus irreverencias, se limita a reproducir lo que recuerda, sin juzgar ni interpretar. Con todo, la metáfora sexual emerge para clausurar con un último sentido cualquier otro registro semántico: en definitiva, la invisibilidad de Caridad es solo comparable a los sentimientos del niño, a medida que este se descubre en relación con los otros: "a lo mejor me estaba pasando algo parecido a lo que le pasaba a la tata Caridad, que me estaba haciendo invisible" (160).

\section{El operativo camp}

Es aceptada como un hecho la relación de continuidad, e incluso de identidad, que tienen el Bildungsroman y la autobiografía o la novela autobiográfica (Kushigian, 1987; Rodríguez Fontela, 1996), géneros que en El palomo cojo se articulan, a su vez, con las memorias y con el modo gótico. Las experiencias de Felipe, relatadas como sucesión de experiencias y de pruebas acompañadas por distintos adultos mentores, dan lugar a un texto a medio camino entre la autobiografía y la novela de formación o Bildungsroman. En relación con las memorias, esta novela entra en diálogo con la tradición bastante consolidada de memorialistas de guerra y de posguerra en la que se destacan Rafael Alberti, Francisco Umbral, Carmen Martín Gaite, Josefina Aldecoa o Eduardo Haro Tecglen ${ }^{3}$. Por último, la composición del ambiente a partir de la casona, del miedo y de la experiencia del despertar sexual de un personaje inocente contribuye a hacer de esta novela un buen ejemplo de relato gótico con sus particularidades inevitablemente ligadas a la conciencia de género sexual que subyace a este tipo de literatura. El elemento gótico, vinculado a una tradición de literatura menor y femenina (Amícola, 2003) contribuye al efecto paródico que aquí comentamos.

Esta suerte de continuum narrativo cristaliza en un espacio de enunciación y de percepción que, como en otras novelas de Eduardo Mendicutti, abreva y se configura en un tipo de sensibilidad específicamente asociada a la percepción gay y en la que la parodia y la resignificación constituyen elementos nucleares. Nos referimos a la sensibilidad camp, cuyo desarrollo en la España postransicional se logró, a nuestro parecer, gracias a la literatura de Eduardo Mendicutti y al cine de Pedro Almodóvar.

En su lectura del camp como expresión acabada del posvanguardismo, José Amícola (2000: 52) interpreta la reutilización y la transformación de la cultura de masas por parte de esa estética (originada en Estados Unidos con el arte pop

${ }^{3}$ Nos referimos a La arboleda perdida de Rafael Alberti, compuesta por dos volúmenes (1977), a Memorias de un niño de derechas (1972) de Francisco Umbral, al ensayo Usos amorosos de la postguerra española (1987) de Carmen Martín Gaite, a la trilogía Historia de una maestra (1990), Mujeres de negro (1994) y La fuerza del destino (1997) de Josefina Aldecoa, y a El niño republicano (1996) de Eduardo Haro Tecglen. 
en los años sesenta, pero con antecedentes durante el periodo clásico del cine de Hollywood) como una crítica de la cultura dominante realizada, paradójicamente, en sus mismos términos. El camp aparece como la manifestación más singular e inasible del último tramo del siglo XX, venida de "los homosexuales", grupo marginalizado e invisibilizado, y puesta en los términos de la cultura dominante al servicio del ataque queer hacia sus convicciones más arraigadas (Amícola, 2000: 48). La obra de Mendicutti, y específicamente la novela El palomo cojo, conforma un ejemplo muy claro de parodización camp de ciertas tradiciones literarias ${ }^{4}$, así como de revalorización positiva de la cultura de masas y de sus códigos puestos al servicio de la configuración de una subjetividad disidente. En este sentido, es importante tener en cuenta las particularidades histórico-culturales de la España franquista durante los años cincuenta, así como la disponibilidad al consumo de productos culturales relativos a la nostalgia y la recuperación memorialística, que caracteriza a la sociedad de los años noventa en adelante.

En la primera aproximación sistemática hacia el camp ${ }^{5}$ hecha en 1964, Susan Sontag (1984: 304-306) lo definió como "una manera de mirar el mundo como fenómeno estético", particularmente asociada al gusto homosexual, en la que se pone el acento sobre el estilo y el artificio (amaneramiento, teatralidad, melodrama), es decir, sobre el "ser impropio de las cosas". Proveniente de una conciencia extravagante y de una sensibilidad "irreprimible, virtualmente incontrolada" (1984: 311), el camp sería, de hecho, la vía de integración de los artistas homosexuales en la sociedad. Como señala Amícola (2000: 52), las mujeres en un principio no se presentaron como productoras de sentido camp, sino que fueron "el objeto obligado de la representación a través de un espejo distorsionante de la supuesta esencia de lo femenino". En términos generales, ante la presión heterosexual compulsiva y los códigos enunciativos hegemónicos que delimitan y coartan las posibilidades de definirse como "persona" (Amícola, 2000: 50) el camp puede pensarse como una manifestación estética del discurso queer. De acuerdo con Moe Meyer (1994: 4), la función del camp es, precisamente, la producción de visibilidad social queer: "thus I define camp as the total body of performative practices and strategies used to enact a queer identity, with enactment defined as the production of social visibility".

La parodia camp es, para Meyer, el proceso por el cual las identidades marginalizadas y privadas de derechos avanzan sobre sus intereses incorporando al discurso códigos de significación alternativos que se anudan a las estructuras de significación preexistentes. Este proceso, que expone las relaciones asimétricas entre un orden dominante, y poseedor del original, y una alteridad que solo cuenta con la alternativa paródica, expresa tensiones y relaciones de poder, en virtud de que es precisamente el orden dominante el que define e instaura códi-

${ }^{4}$ Otros ejemplos de parodia son el relato de ascensión mística de Yo no tengo la culpa de haber nacido tan sexy (1997) y la reescritura del código caballeresco de Los novios búlgaros (1993).

5 El origen del término camp proviene del verbo francés se camper ("plantarse en actitud arrogante, provocativa, ante algo o alguien") (Amícola, 2008: 283). En el slang inglés, camp es un adjetivo que denota afeminamiento, exageración y homosexualidad. 
gos de significación genuinos y a partir de los cuales se establece la producción de valor como prerrogativa de ese orden. Por eso, para Meyer (1994: 9) el encabalgamiento de la parodia sobre el monopolio del orden dominante respecto de la autoridad de la significación produce en el camp el efecto simultáneo de una transgresión y una invocación del espectro de la ideología dominante, situación que en muchos casos puede llevar a creer que el camp estaría precisamente reforzando ese orden. En la tensión entre el original y la copia, la estética camp expresa una forma de continuidad con el pasado y la tradición, pero lo hace obligando al espectador a problematizar los fundamentos de las certezas heterocentradas (Amícola, 2000: 53).

Con El palomo cojo, publicada en el umbral de un periodo de recuperación memorialística que se extiende hasta el presente, el operativo camp irrumpe en el seno de las discusiones sobre la memoria colectiva, al proponer un tipo de representación que desestabiliza y resignifica los lugares comunes del recuerdo colectivo. En esta novela encontramos - permítasenos la división — dos niveles de camp: uno argumental y otro procedimental. En el nivel argumental vemos cómo la composición de los espacios replica el ambiente preferido de los relatos góticos y cómo desfilan a lo largo de las páginas objetos, intereses y amaneramientos propios de una sensibilidad que, como el camp, explota y recicla el $k_{\text {kitsch }}^{6}$ de la cultura de masas (Amícola, 2000: 51-52; Kleinhans, 1994). En lo procedimental, el camp emerge como espacio apto para la parodia de estructuras significativas ligadas a los géneros de la autobiografía y el Bildungsroman, consolidados por una tradición doblemente hegemónica: por masculina y por heterosexual (Amícola 2003 y 2007). A continuación comentaremos, a modo de ejemplos del operativo camp de la novela, algunos de los múltiples guiños culturales que resignifican, por un lado, la tendencia capitalista hacia la nostalgia en el último fin de siglo y, por el otro, las asignaciones aparentemente estables de roles y atributos de género de acuerdo con el sistema de significación binario. En estos objetos, actitudes y gestualidades encontramos un espacio fecundo para la promoción de un tipo de memoria que abarca lugares comunes pertenecientes a los marcos sociales y compartidos de la memoria que describiera Maurice Halbwachs (2004) pero que los transforma, en la reiteración, en función de una clara (y política) misión de visibilización de las identidades abyectas.

En el primer capítulo de la novela, el narrador menciona que por esos años solía pensar en que cuando fuera mayor sería "artista de cine" (17). La neutralidad genérica del adjetivo le permite sostener un equívoco que se decantará hacia el femenino a medida que el relato se adentra en los modelos que el niño adopta para sus identificaciones y que serán la tía Victoria, artista, aunque no de cine, y Sissi, el personaje de la emperatriz austríaca encarnado por Romy Schneider

${ }^{6}$ Entendemos aquí lo kitsch en el sentido general del término, como el arte popular y comercial que imita, sustituye y reproduce el arte alto, de acuerdo con patrones formulaicos y en función de un pretendido buen gusto. 
en la célebre trilogía del director austríaco Ernst Marischka, estrenada entre 1955 y 1957. Felipe fantasea con la edulcorada escena del vals de la princesa con el emperador (en Sissi Emperatriz, de 1956) y se imagina, en contra de las indicaciones de su prima, llevando el vestido de Sissi. Con ironía el narrador explica: “¿y qué culpa tiene uno de lo que sueña? Además, entre un vestido de Sissi y un uniforme de almirante, por bonito que fuera el uniforme, no había ni comparación" (153). La toma de partido por el atuendo glamoroso, máxima exacerbación de lo femenino, recoge un guiño camp que se decodifica en el contexto de una enunciación que apela al lector varón no heterosexual y delimita un terreno común de percepción inserto en los marcos sociales de la memoria relacionados con los recuerdos del ámbito de la cultura de masas. El cineasta Luchino Visconti es otro emblema camp (Sontag, 1984: 305) aludido en El palomo cojo. La presencia invasiva de las palomas del tío Ricardo se resignifica positivamente cuando Victoria mira con ojos empáticos a un ejemplar solitario y cojo, al que bautiza Visconti en homenaje a la sensibilidad, el genio y la elegancia del cineasta italiano (97).

Otros ejemplos de objetos y referencias culturales resignificados como parte del proceso de aprendizaje de Felipe son los "tebeos de amor" y la novela Mujercitas (177-178), lectura muy popular entre las mujeres durante el franquismo. Este libro "emocionante" (178) se transforma, de hecho, en un objeto de culto para la sensibilidad del niño, y es precisamente su lectura la que Felipe lleva a cabo en el inicio del capítulo "Yo tuve un amor secreto" (el segundo de la tercera parte), en el que se recrea en modo camp una típica escena de seducción decimonónica heterosexual, protagonizada en este caso por Felipe y su tío Ramón (181). Si una de las características del camp es, como señala Chuck Kleinhans, su capacidad irónica y al mismo tiempo sentimentalmente comprometida de incorporar y reciclar el kitsch de la cultura de masas (1994: 160), la dualidad narrador/personaje, en cuanto voz adulta del presente y niño inocente del pasado, permite precisamente ese doble juego de teatralidad y autenticidad, ironía e intensidad, al que el lector también es invitado a participar.

Será, por último, una postal muy sentimental hallada entre las pertenencias del tío Ramón (y guardada por Felipe con celoso secreto) otro objeto también kitsch que aglutinará a modo de ícono los aspectos políticos y sexuales disidentes de la novela. Se trata del dibujo de un perro que mira enamorado a un palomo posado sobre la rama de un árbol. La cursilería de la imagen se acompaña de la sentimental dedicatoria de un antiguo amante de Ramón, de nombre Federico (57). El narrador insiste varias veces sobre la carga emocional de su identificación con esa postal, cuyo contenido se aprende de memoria (57), pero lo que no está explícito, y que el lector en efecto repone, es la posibilidad de vincular por homonimia el significante "Federico" con el histórico Federico García Lorca, a quien, como se ha mencionado, la novela rinde homenaje y quien, gracias a las palabras de Victoria, constituye una referencia fuerte para la subjetividad de Felipe: "Creo que contigo — dijo tía Victoria, muy contenta—, Federico va a salir ganando" (202). 


\section{Conclusiones}

La originalidad de la obra de Mendicutti reside, a nuestro juicio, en la reutilización de ciertos significados culturales en función de la emergencia y consolidación de una subjetividad cuyas vivencias no se ajustan a los lugares compartidos del recuerdo colectivo. En contraste con la recuperación de índole sociológicoliteraria que hicieran en sus célebres memorias ensayísticas Francisco Umbral (1972) y Carmen Martín Gaite (1987) en relación con el acervo cultural kitsch y de la cultura de masas que dieran forma a actitudes, creencias y sentimientos de la burguesía española durante el franquismo, el operativo camp de Mendicutti se emplazaría como su reverso no heterocentrado. Esta propuesta transgresora logra, mediante la parodia de géneros literarios, el reciclaje del gótico y la evocación costumbrista, visibilizar la emergencia de una subjetividad disidente precisamente como resultado, de un lado, de procesos de socialización que involucran identificaciones, gustos y saberes propios de burguesía de posguerra (algunos políticamente disidentes y otros, más obedientes, relativos a la construcción de la subjetividad femenina) y, del otro, de modos queer de reiterar y apropiarse de esas conductas.

\section{Referencias bibliográficas}

Amícola, José (2000): Camp y posvanguardia. Manifestaciones culturales de un siglo fenecido, Buenos Aires, Paidós.

Amícola, José (2003): La batalla de los géneros. Novela gótica versus novela de educación, Rosario, Beatriz Viterbo Editora.

Amícola, José (2007): Autobiografía como autofiguración. Estrategias discursivas del Yo y cuestiones de género, Rosario, Beatriz Viterbo Editora.

Assmann, Ian (2008): Religión y memoria cultural. Diez estudios, Buenos Aires, Ediciones Lilmod. Halbwachs, Maurice (2004): Los marcos sociales de la memoria, Barcelona, Anthropos.

Kleinhans, Chuck (1994): "Taking out the trash. Camp and the politics of parody", en Moe Meyer (ed.), The poetics and politics of camp, London, New York, Routledge, pp. 157-173.

Kushigian, Julia (1987): "Transgresión de la autobiografía y el Bildungsroman en Hasta no verte Jesús mío", Revista Iberoamericana, 140, pp. 668-677.

Mendicutti, Eduardo (2001): El palomo cojo, Barcelona, Tusquets.

Rodríguez Fontenla, María de los Ángeles (1996): La novela de autoformación. Una aproximación teórica e histórica al "Bildungsroman" desde la narrativa hispánica, Kassel, Edition Reichenberger.

Sontag, Susan (1984): “Notas sobre lo Camp", en Contra la interpretación y otros ensayos, Barcelona, Seix Barral, pp. 302-321. 


\section{Eduardo Menticutti's El palomo cojo (1991). Towards a Camp Memory}

Keywords: Francoism — collective memory — novel — Eduardo Mendicutti — camp.

\section{Abstract}

The purpose of this work is to analyze Eduardo Mendicutti's El palomo cojo (1991) as a novel about the raising of the abject consciousness within the social, moral and cultural canons of the Francoism Spain during the 1950s. El palomo cojo joints three narrative genres related to the self: autobiography novel, memories and Bildungsroman, and uses also descriptive elements and motifs of the gothic novel. The camp sensibility appears as the semantic and ideological space that gathers and resignifies these multiple narrative inscriptions.

Fecha de recepción: 2 de junio de 2020

Fecha de aceptación: 22 de julio de 2020 